Nat. Hazards Earth Syst. Sci. Discuss., https://doi.org/10.5194/nhess-2017-325

Manuscript under review for journal Nat. Hazards Earth Syst. Sci.

Discussion started: 26 October 2017

(c) Author(s) 2017. CC BY 4.0 License.

\title{
Bag-of-words-based anomaly-detection principal component analysis and stochastic optimization for debris flow detection and evacuation planning
}

\author{
Chia-Chun Kuo ${ }^{1}$, Yi-Ren $\mathrm{Yeh}^{2}$, Kuan-wen $\mathrm{Chou}^{3}$, Chien-Lin Huang ${ }^{3}$, Ming-Che $\mathrm{Hu}^{1}$
}

$5{ }^{1}$ Department of Bioenvironmental Systems Engineering, National Taiwan University, No. 1, Sec. 4, Roosevelt Road, Taipei 10617, Taiwan

${ }^{2}$ Department of Mathematics, National Kaohsiung Normal University, No. 62, Shenjhong Road, Yanchao District, Kaohsiung, Taiwan

${ }^{3}$ hetengtech Company Limited, Rm. 6A, 2F., No. 7, Sec. 3, New Taipei Blvd., Xinzhuang Dist., New Taipei City 242, Taiwan

10 Correspondence to: Ming-Che Hu (mchu@ntu.edu.tw)

\begin{abstract}
Debris flows are natural disasters, with soil mass, rocks, and water traveling down a mountainside slope. Debris flows are extremely dangerous; their occurrence incurs huge losses to life and property. The purpose of this research is to develop debris flow detection and emergency evacuation systems. A bag-of-words model is established for analyzing the features of debris flow events, and an anomaly-detection principal component analysis (PCA) model is proposed to detect

15 debris flow. Using real-time debris flow prediction and monitoring, a stochastic optimization model for evacuation planning is formulated. Case studies of debris flow detection in Shenmu village and Fengchiu, central Taiwan, are conducted. Shenmu village and Fengchiu are areas of high potential debris flow, and each has a population of around 800 people. The results show that combining bag-of-words and anomaly-detection PCA methods could predict 6 out of 8 occurrences of actual events, providing a prediction rate of $75 \%$. In addition, the models make 13 predictions, and 6 of them are correct, providing a

20 prediction accuracy of $46 \%$. Optimal parameters (including window size, bag length, filter ratio of training data, and anomaly threshold) of the models are also examined to increase the accuracy of debris flow prediction.
\end{abstract}

Keywords: debris flow, bag-of-words, anomaly-detection, stochastic optimization

\section{Introduction}

Debris flows can be triggered by intense rainfall, floods, earthquakes, snowmelt, dam-breaks, and other geological factors (Promper et al., 2015; Chen et al., 2016; Masaba et al., 2017; Takahashi, 1981; Keefer et al., 1987). Debris flows bring soil masses, water, rocks, and mud down mountainside slopes by gravity. Debris flows are extremely dangerous disasters, and occur frequently on mountainsides worldwide. Serious damage to residents, private property, buildings, roads, and bridges has been caused by debris flows in the past (Wieczorek, 1987; Cheng et al., 2005; Fan et al., 2015; Calvello et al., 2015; Manandhar et al., 2015). Since 2002, the Taiwan Soil and Water Conservation Bureau (Taiwan SWCB) has installed 24 fixed stations for debris flow observation, as well as various monitoring devices in areas at high risk from debris flows. With the data obtained 
Nat. Hazards Earth Syst. Sci. Discuss., https://doi.org/10.5194/nhess-2017-325

Manuscript under review for journal Nat. Hazards Earth Syst. Sci.

Discussion started: 26 October 2017

(c) Author(s) 2017. CC BY 4.0 License.

from these debris flow monitoring systems, this research proposes innovative machine learning methods for capturing debris flow features, and establishes stochastic optimization for emergency evacuations. A smart system for detecting debris flows and preventing slopeland disasters is also established.

This study newly proposes a bag-of-words method to re-interpret debris flow data and enhance computational efficiency.

35 Then, an anomaly-detection principal component analysis (anomaly-detection PCA) model is developed to create a debris flow warning system by detecting data related to abnormal debris flow characteristics. A stochastic programming model is also established for emergency evacuation.

The bag-of-words method is a sequential feature-learning algorithm used for pattern recognition, computational learning, artificial intelligence, simulation, and predication (Lin et al., 2012; Gui and Yeh, 2014). Text documents, sentences, and

40 paragraphs are a conglomerate of words, and the bag-of-words model breaks down text into words and analyzes the frequency of each word.

An anomaly-detection PCA is a statistical method for detecting abnormal data on a principal coordinates system (Candès et al., 2011; Lee et al., 2013). The principal coordinates of eigenvalue problems are identified for different data covariance matrixes. Then, the anomaly-detection PCA detects abnormal data by measuring the impact of new data on principal directions. The impact on principal directions is used to identify abnormal/outlier data.

Stochastic optimization is an optimization model for uncertainty (Barbarosoglu and Arda, 2004; Bretschneider, 2012; Bozorgi-Amiri et al., 2013; Pourrahmani et al., 2015; Wood et al., 2016; Xu et al., 2016; Azam et al., 2017). In the case of two-stage stochastic optimization, two decision stages are separated by uncertain events. The decisions made in the first stage are here-and-now decisions, before the uncertainty occurred; the decisions at the second stage are wait-and-see decisions, after

50 the occurrence of uncertainty. In the case of sequential uncertain events, the model can be extended to multi-stage stochastic optimization. This research applies stochastic optimization for evacuation planning if a debris flow occurs.

Previous studies have applied machine learning algorithms (including support vector machines (SVM), decision tree, logistic regression, Bayesian, fuzzy, neural network, etc.) to analyze and predict natural disaster events (Lee and Pradhan, 2007; Dean and Ghemawat, 2008). Yao et al. (2008) formulated SVM to analyze landslide susceptibility mapping in Hong

55 Kong. They used slope angle, slope aspect, elevation, profile curvature of slope, lithology, vegetation cover, and topographic wetness index (TWI) as environmental parameters to categorize the occurrence of landslides. Marjanovic et al. (2011) compared SVM, decision trees, and logistic regression algorithms. In these machine learning algorithms, geological, morphological, and environmental attributes are used to predict landslide susceptibility assessment. Xu et al. (2012) developed a GIS-based SVM model to examine the earthquake-triggered landslide in the Jianjiang River watershed. Pradhan (2013)

60 compared the decision tree, SVM, and adaptive neuro-fuzzy inference system (ANFIS) for examining potential landslide occurrences in the Penang Hill area. Liang et al. (2012) developed a novel approach for assessing debris flow hazard risk using a Bayesian Network (BN) and domain knowledge. In this study, an SVM and Artificial Neural Network (ANN) were compared with a BN. 
Nat. Hazards Earth Syst. Sci. Discuss., https://doi.org/10.5194/nhess-2017-325

Manuscript under review for journal Nat. Hazards Earth Syst. Sci.

Discussion started: 26 October 2017

(c) Author(s) 2017. CC BY 4.0 License.

Some previous studies have applied bag-of-words and anomaly-detection methods for environmental, biomedical,

65 human, traffic, and computer science analyses. Khan et al. (2011) established a homography-based visual bag-of-words model to perform scene localization in indoor environments. Behley et al. (2013) combined multiple softmax regression classifiers learned from specific bag-of-word representations, proposing a segment-based object detection approach using laser range data. Wang et al. (2013) applied bag-of-words representation for biomedical time series classification, and their experimental results demonstrated that the method was insensitive to the parameters (i.e., local segment length and codebook size) of the

70 bag-of-words model and robust to noise. Baydogan et al. (2013) presented a bag-of-features framework to classify time series data. The experimental results show that the bag-of-features framework provided better results than competitive methods on benchmark datasets from the UCR time series database. Gui and Yeh (2014) developed a temporal bag-of-words model for time series classification. Their method was applied to user identification by a door opening and closing trajectory. Ringberg et al. (2007) conducted a sensitivity analysis of PCA for traffic anomaly detection and analyzed network-wide traffic measurements from two IP backbones (Abilene and Geant) across three different traffic aggregations. Brauckhoff et al. (2009) proposed a spatial PCA for network-wide anomaly detection. They compared the PCA with a Karhunen-Loeve expansion, since PCAs are very sensitive to calibration settings. Lee et al. (2013) conducted anomaly detection via online oversampling PCA, and compared with other anomaly-detection algorithms, the online oversampling PCA provided feasibility in terms of accuracy and efficiency.

Compared with previous, related studies, the significant contributions of this research include innovative development and the application of bag-of-words, anomaly-detection PCA, stochastic optimization methods, and integrated frameworks for debris flow detection and evacuation. Case studies in high potential debris flow areas, Shenmu village and Fengchiu, are also conducted. This paper is organized as follows. Section 2 expresses the methodology, including the bag-of-words models and stochastic evacuation optimization. Section 3 conducts case studies of debris flows in Taiwan, and the results are discussed.

85 Section 4 presents the conclusions.

\section{Methods}

This section formulates the bag-of-words model and anomaly-detection PCA for debris flow prediction. With observations and predictions, a real-time stochastic optimization method is established for debris flow evacuation planning.

The bag-of-words method is introduced as follows (Gui and Yeh, 2014). Eq. (1) defines $\mathrm{X}^{\mathrm{i}}$ to be vector variables

90 representing $\mathrm{i}$ - th time series debris flow data. Subsequences with window $\mathrm{w}$ are extracted from the time series data. The number of subsequences of $X^{i}$ is $p-(w-1)$, since the length of $\left(x_{w-1}^{i}, \ldots, x_{1}^{i}\right)$ at the end of the time series data is less than number of windows $w$. Suppose there is $n$ time series data, then the total number of subsequences is $(n) \times[p-(w-1)]$. Further, in Eq. (2), $\mathrm{y}^{\mathrm{i}}$ is denoted as class variables of time series $\mathrm{X}^{\mathrm{i}}$.

$\mathrm{X}^{\mathrm{i}}=\left(\mathrm{x}_{\mathrm{p}}^{\mathrm{i}}, \mathrm{x}_{\mathrm{p}-1}^{\mathrm{i}}, \mathrm{x}_{\mathrm{p}-2}^{\mathrm{i}}, \ldots, \mathrm{x}_{\mathrm{w}}^{\mathrm{i}}, \mathrm{x}_{\mathrm{w}-1}^{\mathrm{i}}, \ldots, \mathrm{x}_{1}^{\mathrm{i}}\right)$ 
Nat. Hazards Earth Syst. Sci. Discuss., https://doi.org/10.5194/nhess-2017-325

Manuscript under review for journal Nat. Hazards Earth Syst. Sci.

Discussion started: 26 October 2017

(c) Author(s) 2017. CC BY 4.0 License.

(c) (i)
Natural Hazards

and Earth System

Sciences

Discussions

$95 y^{\mathrm{i}}=(1,2, \ldots, \mathrm{c})$

$\forall \mathrm{i}$

Time series data are divided into two sets of data for model training and testing. Time series data are disaggregated into subsequences with length $\mathrm{w}$ for training. A k-means method is applied to cluster $\mathrm{d}$ centroids. The set of centroids are referred to as words for the bag-of-words method. The $\mathrm{d}$ subsequences of centroids are the elementary components for predicting unknown time series data.

The test time series data is broken into subsequences, with window $\mathrm{w}$, and the closest centroid is sought for each subsequence. The denote $h_{j}$ is used as the centroid index for each subsequence. The $h_{j}=1$ while jth centroid is the closest centroid, and $h_{j}=0$ suggests otherwise. The closest centroid is found for each subsequence, then all subsequences are categorized with vector indices, represented by H in Eq. (3). Only one of $h_{j}$ is equal to one, and the rest are equal to zero, so the summing of vector indices over all of the subsequences in time series data yields combination of centroid for the data. The summation vector indices of a time series dataset represent the occurrence frequency of centroids, so the testing time series data can be predicted and categorized.

$\mathrm{H}=\left(\mathrm{h}_{1}, \mathrm{~h}_{2}, \mathrm{~h}_{3}, \ldots, \mathrm{h}_{\mathrm{d}}\right)$

An anomaly-detection PCA is applied to analyze the bag-of-words results for detecting debris flow events. PCA is an orthogonal transformation method for dimension reduction [Lee et al., 2013]. The data of observation $\mathrm{K}$ is denoted as data ${ }_{\mathrm{k}}$,

110 and $\mu$ is the mean of the observation data. $\sum_{k}\left[\left(\right.\right.$ data $\left.\left._{k}-\mu\right)\left(\text { data }_{k}-\mu\right)^{T}\right] / n$ calculates data variance and its matrix form represents the covariance matrix $\mathrm{V}$ in Eq. (4). If $\mathrm{U}$ is the unit vector of principal coordinates, multiplying the left by $\mathrm{U}^{\mathrm{T}}$, and the right by $U$, yields the variance of the principal coordinates data in Eq. (5). PCA then determines the principal coordinates by maximizing variance in Eq. (5). Solving the variance maximizing problem of PCA produces eigenvectors, U, of the covariance matrix, COV. Alternatively, the principal axis can be decided by minimizing the data reconstruction error in Eq. (6).

115 The data reconstruction error is equal to the original data, $\left(\right.$ data $\left._{\mathrm{k}}-\mu\right)$, minus data reconstruction, $\mathrm{UU}^{\mathrm{T}}\left(\right.$ data $\left._{\mathrm{k}}-\mu\right)$.

$\mathrm{V}=\sum_{\mathrm{k}}\left[\left(\right.\right.$ data $\left.\left._{\mathrm{k}}-\mu\right)\left(\text { data }_{\mathrm{k}}-\mu\right)^{\mathrm{T}}\right] / \mathrm{n}$

$\underset{\|U\|=1}{\operatorname{MAX}} \sum_{\mathrm{k}}\left[\mathrm{U}^{\mathrm{T}}\left(\right.\right.$ data $\left.\left._{\mathrm{k}}-\mu\right)\left(\text { data }_{\mathrm{k}}-\mu\right)^{\mathrm{T}} \mathrm{U}\right]$

$\underset{\|U\|=1}{\operatorname{MIN}} \sum_{\mathrm{k}} \|\left(\right.$ data $\left._{\mathrm{k}}-\mu\right)-\mathrm{UU}^{\mathrm{T}}\left(\right.$ data $\left._{\mathrm{k}}-\mu\right) \|$

The anomaly-detection PCA measures the impact of abnormal outlier data on principal directions. If A represents all of

120 the observed data, then leaving one data, $x_{t}$, out of $A$ gives $A 1$, i.e., $A 1=A \backslash\left\{x_{t}\right\} . V_{A}$ and $V_{A 1}$ are the covariance matrices of $A$ and A1, calculated in Eqs. (7) and (8). The principal coordinates are determined by solving the eigenvectors of the covariance matrix in Eqs. (9) and (10). The impact of abnormal outlier data is measured by the differences of PCA principal directions in Eq. (11). A larger number of $s$ in Eq. (11) indicates a large change in principal directions by anomaly data.

In contrast, adding one data point $x_{t}$ to $A$ yields $A 2$, i.e., $A 2=A \cup\left\{x_{t}\right\} . V_{A 2}$ is the covariance matrix of $A 2$, calculated in Eq. (12). The updated eigenvector is estimated in Eq. (13). The impact of adding new data is measured by Eq. (14). 
Nat. Hazards Earth Syst. Sci. Discuss., https://doi.org/10.5194/nhess-2017-325

Manuscript under review for journal Nat. Hazards Earth Syst. Sci.

Discussion started: 26 October 2017

(C) Author(s) 2017. CC BY 4.0 License.
Natural Hazards

and Earth System

Sciences

Discussions

Changes in principal direction by adding just one data is not significant if the original size of the dataset is relatively large. Duplicating $x_{t}$ by $n 1$ times and adding $\left\{x_{t}, x_{t}, \ldots, x_{t}\right\}$ to $A$ yields $A 3$, i.e., $A 3=A \cup\left\{x_{t}, x_{t}, \ldots, x_{t}\right\} . V_{A 3}$ is the covariance matrix of A3, calculated in Eq. (15). A new eigenvector is calculated in Eq. (16), and the impact of adding n1, new data, is measured by Eq. (17).

$\mathrm{V}_{\mathrm{A}}=\frac{1}{(n)} \sum_{x_{i} \in \mathrm{A}}\left(x_{i}-\bar{x}_{i}\right)\left(x_{i}-\bar{x}_{i}\right)^{T}$

$\mathrm{V}_{\mathrm{A} 1}=\frac{1}{(n-1)} \sum_{x_{i} \in \mathrm{A} \backslash\left\{\mathrm{x}_{\mathrm{t}}\right\}}\left(x_{i}-\bar{x}_{i}\right)\left(x_{i}-\bar{x}_{i}\right)^{T}$

$\mathrm{V}_{\mathrm{A}}\left(\mathrm{u}_{\mathrm{A}}\right)=\lambda_{\mathrm{A}}\left(\mathrm{u}_{\mathrm{A}}\right)$

$\mathrm{V}_{\mathrm{A} 1}\left(\mathrm{u}_{\mathrm{A} 1}\right)=\lambda_{\mathrm{A} 1}\left(\mathrm{u}_{\mathrm{A} 1}\right)$

$\mathrm{s}=1-\left|\left\langle\mathrm{u}_{\mathrm{A}}, \mathrm{u}_{\mathrm{A} 1}\right\rangle /\left(\left\|\mathrm{u}_{\mathrm{A}}\right\||| \mathrm{u}_{\mathrm{A} 1} \|\right)\right|$

$135 \mathrm{~V}_{\mathrm{A} 2}=\frac{1}{(n+1)}\left[\left(x_{t}-\bar{x}_{i}\right)\left(x_{t}-\bar{x}_{i}\right)^{T}+\sum_{x_{i} \in \mathrm{A}}\left(x_{i}-\bar{x}_{i}\right)\left(x_{i}-\bar{x}_{i}\right)^{T}\right]$

$\mathrm{V}_{\mathrm{A} 2}\left(\mathrm{u}_{\mathrm{A} 2}\right)=\lambda_{\mathrm{A} 2}\left(\mathrm{u}_{\mathrm{A} 2}\right)$

$\mathrm{s}=1-\left|\left\langle\mathrm{u}_{\mathrm{A}}, \mathrm{u}_{\mathrm{A} 1}\right\rangle /\left(\left\|\mathrm{u}_{\mathrm{A}}\right\|\left\|\mathrm{u}_{\mathrm{A} 1}\right\|\right)\right|$

$\mathrm{V}_{\mathrm{A} 3}=\frac{1}{(n+n 1)}\left[(n 1)\left(x_{t}-\bar{x}_{i}\right)\left(x_{t}-\bar{x}_{i}\right)^{T}+\sum_{x_{i} \in \mathrm{A}}\left(x_{i}-\bar{x}_{i}\right)\left(x_{i}-\bar{x}_{i}\right)^{T}\right]$

$\mathrm{V}_{\mathrm{A} 3}\left(\mathrm{u}_{\mathrm{A} 3}\right)=\lambda_{\mathrm{A} 3}\left(\mathrm{u}_{\mathrm{A} 3}\right)$

$140 \mathrm{~s}=1-\left|\left\langle\mathrm{u}_{\mathrm{A}}, \mathrm{u}_{\mathrm{A} 1}\right\rangle /\left(\left\|\mathrm{u}_{\mathrm{A}}\right\|\left\|\mathrm{u}_{\mathrm{A} 1}\right\|\right)\right|$

Stochastic optimization models and tradeoff analysis of evacuation problems will now be discussed. trans ${ }_{\mathrm{e}, \mathrm{f}, \mathrm{g}, \mathrm{h}}$ is the number of people traveling from node e to $\mathrm{f}$ at time $\mathrm{g}$ for scenario $\mathrm{h}$. resident $\mathrm{e}$ is the people that need to be evacuated at node $\mathrm{e}$, and shelter $\mathrm{f}_{\mathrm{h}, \mathrm{h}}$ is number of people evacuated to shelter $\mathrm{f}$. Additionally, sheltercost $\mathrm{f}_{\mathrm{f}}$ represents the construction cost of new shelter capacity at node $f$. transcost ${ }_{e, f}$ denotes the construction cost of new transportation capacity between nodes e and $\mathrm{f}$.

145 TIMECOST $_{\mathrm{e}, \mathrm{f}}$ is the average traveling time from node e to $\mathrm{f}_{\mathrm{PROB}} \mathrm{h}$ is the probability of a stochastic debris flow scenario, $\mathrm{h}$. Eq. (18) calculates the weighted average of facility expansion cost, plus expected evacuation time. Eq. (19) confines the people living in the evacuation area that need to be evacuated. In Eq. (20), a mass balance equation defines whether total inflow is equal to total outflow at node e. Eq. (21) calculates the total people evacuated to shelter f for scenario h. Eq. (22) determines if all residents are evacuated. transcap $\mathrm{e}_{\mathrm{f}}$ and transnewcap $\mathrm{e}_{\mathrm{f}}$ are the existing and new transportation capacities between nodes e and f. The transportation capacity constraint is established in Eq. (23). The existing and new shelter capacities at node f are presented by sheltercap $\mathrm{f}_{\mathrm{f}}$ and shelternewcap $\mathrm{f}$ and shelter capacity is formulated in Eq. (24). Nonnegativity constraints are established in Eq. (25), and according to the bag-of-words-based anomaly-detection PCA prediction, and real-time monitoring, debris flow evacuation is planned based on the stochastic optimization model in Eqs. (18)-(25).

Minimize 
Nat. Hazards Earth Syst. Sci. Discuss., https://doi.org/10.5194/nhess-2017-325

Manuscript under review for journal Nat. Hazards Earth Syst. Sci.

Discussion started: 26 October 2017

(c) Author(s) 2017. CC BY 4.0 License.

$\sum_{\mathrm{e}, \mathrm{f}}\left[\operatorname{transcost}_{\mathrm{e}, \mathrm{f}} \times\right.$ transnewcap $\left._{\mathrm{e}, \mathrm{f}}\right]+\sum_{\mathrm{f}}\left[\right.$ sheltercost $_{\mathrm{f}} \times$ shelternewcap $\left._{\mathrm{f}}\right]$

$$
+\sum_{\mathrm{h}}\left[\left(\operatorname{prob}_{\mathrm{h}}\right) \times\left(\sum_{\mathrm{e}, \mathrm{f}, \mathrm{g}}\left[\operatorname{TIMECOST}_{\mathrm{e}, \mathrm{f}} \times \text { trans }_{\mathrm{e}, \mathrm{f}, \mathrm{g}, \mathrm{h}}\right]\right)\right]
$$

Subject to

$\sum_{\mathrm{f} \in \mathrm{ADJ}(\mathrm{e})}$ trans $_{\mathrm{e}, \mathrm{f}, \mathrm{g}, \mathrm{h}}=$ resident $_{\mathrm{e}}$

$$
\begin{aligned}
& \forall \mathrm{e}, \mathrm{f} \notin \mathrm{m}, \mathrm{g}=1, \mathrm{~h} \\
& \forall \mathrm{e}, \mathrm{g} \neq 1, \mathrm{~h} \\
& \forall \mathrm{f}, \mathrm{h} \\
& \forall \mathrm{h} \\
& \forall \mathrm{e}, \mathrm{f}, \mathrm{g}, \mathrm{h} \\
& \forall \mathrm{f}, \mathrm{h} \\
& \forall \mathrm{e}, \mathrm{f}, \mathrm{g}, \mathrm{h} \\
& \forall \mathrm{e}, \mathrm{f}
\end{aligned}
$$

\section{Results and discussion}

Case studies of debris flows in Shenmu village and Fengchiu, central Taiwan, are conducted in this section. The bag-of-words and anomaly-detection PCA methods are applied to predict the occurrence of a debris flow, and the results are compared with the traditional effective accumulative rainfall prediction and red warning systems by Taiwan SWCB.

Shenmu village and Fengchiu are located in Nantou, Taiwan (Fig. 1). Shenmu village has an area of $77 \mathrm{~km}^{2}$, with a population of 750 people; Fengchiu has an area of around $25 \mathrm{~km}^{2}$ and a population of 770 people. Shenmu village and Fengchiu are areas of high potential debris flow risk. They are located in the Chenyulan stream watershed, and the locations are close to the convergence of the Heshe, Shenmu, and Chushui streams (Chenyulan stream's tributary). The debris flow monitoring stations and warning systems in Shenmu village and Fengchiu were established in 2002.

In Shenmu village, the Typhoon Herb in 1996 brought an accumulated rainfall of approximately $600 \mathrm{~mm}$ in 24 hours, and a maximum rainfall rate of $74 \mathrm{~mm} /$ hour. Debris flows of 450,000 $\mathrm{m}^{3}$ were triggered within 5.5 hectares of Shenmu village, causing five deaths and injuring six people. Furthermore, Typhoon Toraji in 2001, Typhoon Mindulle in 2004, and Typhoon Morakot in 2009 brought a record-high rainfall that caused serious debris flows, landslide, flooding, leading to damage to life, private property, transportation, water, food, and electricity supplies in Shenmu village. Fengchiu is also an area of high potential debris flow risk. Typhoon Herb caused two deaths and destroyed houses, fruit orchard, roads, dams, and hydraulic constructions. The Chi-Chi earthquake and Typhoon Toraji in 2001 caused severe landslides and debris flows in Fengchiu.

A framework of debris flow detection and evacuation planning is constructed here, with the flowchart plotted in Fig. 2. Time series data for rainfall and soil water content are collected and separated into training and testing data. The bag-ofwords method is applied to check the occurrence of rainfall subsequence data. After training the model, an anomaly-detection 
Nat. Hazards Earth Syst. Sci. Discuss., https://doi.org/10.5194/nhess-2017-325

Manuscript under review for journal Nat. Hazards Earth Syst. Sci.

Discussion started: 26 October 2017

(c) Author(s) 2017. CC BY 4.0 License.

185 PCA is used to measure the impact of testing data. Abnormal outlier data is detected by quantifying the change in principal directions.

The effective accumulative rainfall method and red warnings are used by Taiwan SWCB to predict debris flows. These two methods are compared with the bag-of-words and anomaly-detection PCA methods. Eq. (26) calculates the effective accumulative rainfall, EAR, which is equal to the weighted sum of current rainfall RAIN ${ }_{0}$ and previous rainfall RAIN . The weights are one for current rainfall, and $(\alpha)^{S}$ for the rainfall that occurred s days previously. Taiwan SWCB assumes that discounting factor $\alpha$ equals 0.7 , and the length of time for previous rainfall data is seven days (i.e., $\mathrm{s}=1,2,3, \ldots, 7$ ). Taiwan SWCB also provide a red warning for debris flow events on the basis of the EAR method, as well as meteorological data and expert judgment.

$\mathrm{EAR}=\mathrm{RAIN}_{0}+\sum_{\mathrm{s}}\left[(\alpha)^{\mathrm{s}} \times \mathrm{RAIN}_{\mathrm{s}}\right]$

Table 1 shows the bag-of-words and anomaly-detection PCA prediction of debris flows in Shenmu village between 2011 and 2015. The bag-of-words and anomaly-detection PCA methods predict 13 anomaly data, while there are eight actual debris flow events. This research uses two indicators to compare prediction methods, including prediction rate and prediction accuracy (Table 1). Prediction rate measures the prediction percentage of actual debris flows, and prediction accuracy is the correct rate of prediction. The bag-of-words and anomaly-detection PCA methods are able to predict six out of eight actual events, and the prediction rate is $75 \%$. The method projects 13 events, six of which are correct, and provides a prediction accuracy of $46 \%$.

The effective accumulative rainfall and red warning methods used by Taiwan SWCB are tested and compared with our methods. In Table 1, both effective accumulative rainfall method and red warming predicted two out of eight actual events between 2011 and 2015. The prediction rates are 25\% for both of the Taiwan SWCB methods. The effective accumulative rainfall method predicts eight possible events, providing a prediction accuracy of $25 \%$. The red warning method presents a prediction accuracy of $29 \%$ by projecting seven potential events.

The bag-of-words and anomaly-detection PCA methods are applied to predict debris flows in Fengchiu. Table 2 shows that, between 2011 and 2015, only one actual debris flow event occurred on May 03, 2012. The bag-of-words and anomalydetection PCA methods are able to correctly predict the actual debris flow event, so the prediction rate is $100 \%$. The models detect four anomaly subsequences with one correct prediction, while a prediction accuracy of $25 \%$ is provided.

Window size, length of bag, filter ratio of training data, and anomaly thresholds are important parameters of the bagof-words and anomaly-detection PCA methods. Those parameters are examined for the case studies. Window size represents the length of subsequences, and a large window size indicates greater variation of words in the bag-of-words method and a small window size provides high computational efficiency. Length of bag is the number of words in the method. A large length 215 of bag provides more basic components (i.e., more words) for the bag-of-words method. The filter ratio of training data represents the anomaly ratio of training data that should be deleted. The remaining training data are processed to train the anomaly-detection PCA. A high filter ratio provides less normal training data, while a low ratio treats most training data as 
Nat. Hazards Earth Syst. Sci. Discuss., https://doi.org/10.5194/nhess-2017-325

Manuscript under review for journal Nat. Hazards Earth Syst. Sci.

Discussion started: 26 October 2017

(c) Author(s) 2017. CC BY 4.0 License.

normal. The anomaly threshold is the standard for measuring the impact of principal components and detecting anomaly data. A high anomaly threshold predicts more debris flow events with low accuracy. In contrast, a low anomaly threshold leads to high prediction accuracy, but fewer events could be simulated. Optimal parameters are determined for the case studies of Shenmu village and Fengchiu. To maximize prediction accuracy, the optimal filter ratio and anomaly threshold of Shenmu village are 0.1 and 0.025 . The optimal filter ratio and anomaly threshold for Fengchiu are 0.05 and 0.02 . The optimal window size and length of bag are 4 and 15. The results show that increasing window size and length of bag requires more computation, but does not provide better prediction accuracy.

In Shenmu village, the debris flows on July, 13th, 2011 and November 10th, 2011 are not predicted by our bag-ofwords and anomaly-detection PCA methods. Figs. 3-6 plot the rainfall data and soil water content of those two events. Figs. 3 and 5 present 7-days of accumulative rainfall, which are $85.0 \mathrm{~mm}$ and $56.5 \mathrm{~mm}$ on the July, 13th, 2011 and November 10th, 2011 events. Figs. 4 and 6 display average soil water contents of $60.1 \%$ and $61.7 \%$ on the July, 13th, 2011 and November 10th, 2011 events. Compared with historical debris flow data, these two debris flows have relatively low accumulative rainfall and average water content. Hence, those extreme events are not predicted by the models.

\section{Conclusions}

This research establishes a bag-of-words model to analyze the occurrence of debris flows and proposes an anomaly-detection PCA method for debris flow prediction. Additionally, a stochastic programming model is formulated to optimize real-time evacuation planning. The significance of this research includes innovative development and application of machine-learning and optimization methodologies for debris flow prediction and evacuation planning.

In the case study, the bag-of-words and anomaly-detection PCA methods simulate and predict the occurrence of debris flows in Shenmu village in the Chen-Yu-Lan stream watershed, Taiwan. The results show a 75\% prediction rate (of eight debris flow events) and $46 \%$ prediction accuracy (out of 13 trials). Stochastic optimization of debris flow evacuation planning is also established. Overall, a framework for debris flow detection and evacuation is developed. Optimal parameters of window size, length of bag, filter ratio of training data, and anomaly threshold are analyzed for the bag-of-words and anomaly-detection PCA methods. By optimizing these parameters, prediction accuracy of debris flows in Shenmu village and Fengchiu is increased. Future studies include improvement of debris flow prediction and detection, development of disaster warning and response systems, and practical tests and application in areas at risk of debris flows.

\section{Acknowledgments}

245 The authors wish to thank the editors and anonymous referees for their thoughtful comments and suggestions. The authors are solely responsible for all opinions expressed in this paper and any remaining errors. This research was funded by the Taiwanese Ministry of Science and Technology (MOST) under Grant MOST-105-2627-M-002-037 (105T612C502). 
Nat. Hazards Earth Syst. Sci. Discuss., https://doi.org/10.5194/nhess-2017-325

Manuscript under review for journal Nat. Hazards Earth Syst. Sci.

Discussion started: 26 October 2017

(c) Author(s) 2017. CC BY 4.0 License.

(c) (i)

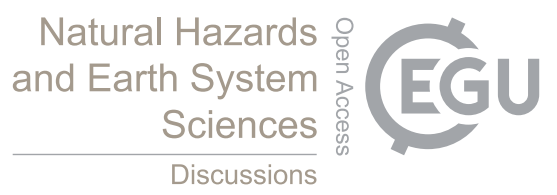

\section{Nomenclature}

In this paper, indices and decision variables use lowercase letters. Uppercase letters indicate given coefficients. The indices,

250 coefficients, decision variables, and their definitions are listed below.

Indices

i time series, $\mathrm{i}=1,2, \ldots, \mathrm{n}$

j centroid, $\mathrm{i}=1,2, \ldots, \mathrm{d}$

$\mathrm{k} \quad$ observation, $\mathrm{k}=1,2, \ldots, \mathrm{K}$

$255 \mathrm{~s} \quad$ day, $\mathrm{s}=1,2, \ldots, \mathrm{S}$

e, $f \quad$ node of evacuation network

g evacuation time

h stochastic scenario

Variables

260 A

all observed data

A1 removing $\mathrm{x}_{\mathrm{t}}$ to all observed data, i.e., $\mathrm{A} 1=\mathrm{A} \backslash\left\{\mathrm{x}_{\mathrm{t}}\right\}$

A2 adding $x_{t}$ to all observed data, i.e., $A 2=A \cup\left\{x_{t}\right\}$

A3 adding $x_{t}$ to all observed data, i.e., $A 3=A \cup\left\{x_{t}, x_{t}, \ldots, x_{t}\right\}$

c number of time series class

$265 \mathrm{~d}$ number of centroids for k-means method

data $_{\mathrm{k}} \quad$ data of observation $\mathrm{K}$

EAR effective accumulative rainfall

$h_{j} \quad$ index of closest centroid

$\mathrm{H} \quad$ index vector of $h_{j}$ of closest centroid

$270 \mathrm{n} \quad$ number of time series

$\mathrm{p} \quad$ number of elements of a time series

RAIN $_{0} \quad$ current rainfall

RAIN $_{\mathrm{s}} \quad$ previous rainfall of $\mathrm{s}$ days beforehand

$\mathrm{U} \quad$ principal directions

$275 \mathrm{u}_{\mathrm{A}} \quad$ eigenvector of covariance matrix of data $\mathrm{A}$

$\mathrm{u}_{\mathrm{A} 1} \quad$ eigenvector of covariance matrix of data $\mathrm{A} 1$

$\mathrm{u}_{\mathrm{A} 2} \quad$ eigenvector of covariance matrix of data $\mathrm{A} 2$

$\mathrm{u}_{\mathrm{A} 3} \quad$ eigenvector of covariance matrix of data $\mathrm{A} 3$

$\mathrm{V}_{\mathrm{A}} \quad$ covariance matrix of data $\mathrm{A}$ 
Nat. Hazards Earth Syst. Sci. Discuss., https://doi.org/10.5194/nhess-2017-325

Manuscript under review for journal Nat. Hazards Earth Syst. Sci.

Discussion started: 26 October 2017

(c) Author(s) 2017. CC BY 4.0 License.

(c) (i)

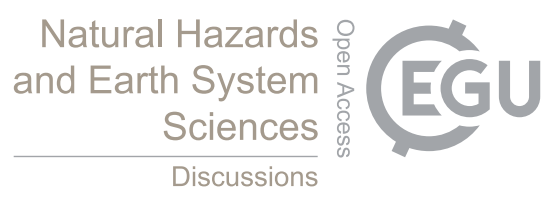

$280 \mathrm{~V}_{\mathrm{A} 1}$

$\mathrm{V}_{\mathrm{A} 2}$

$\mathrm{V}_{\mathrm{A} 3}$

$\mathrm{W}$

$x_{p}^{i}$

$285 \mathrm{X}^{\mathrm{i}}$

$\mathrm{y}^{\mathrm{i}}$

$\alpha$

$\lambda_{\mathrm{A}}$

$\lambda_{\mathrm{A} 1}$

$290 \lambda_{\mathrm{A} 2}$

$\lambda_{\mathrm{A} 3}$

$\mu$

$\operatorname{ADJ}(\mathrm{e})$

$\mathrm{PROB}_{\mathrm{h}}$

295

resident $_{\mathrm{e}}$

shelter $_{\mathrm{f}, \mathrm{h}}$

covariance matrix of data $\mathrm{A} 1$

covariance matrix of data $\mathrm{A} 2$

covariance matrix of data $\mathrm{A} 3$

length of window; number of subsequence elements

element of time series vector

time series i

class variables of time series $\mathrm{X}^{\mathrm{i}}$

discounting factor of effective accumulative rainfall method

eigenvalue of covariance matrix of data $\mathrm{A}$

eigenvalue of covariance matrix of data $\mathrm{A} 1$

eigenvalue of covariance matrix of data $\mathrm{A} 2$

eigenvalue of covariance matrix of data $\mathrm{A} 3$

mean of observation data

adjacent nodes of node e

probability of stochastic debris flow scenario $h$

people needed to be evacuated at node e

number of persons evacuated to shelter at node $f$ for scenario $h$

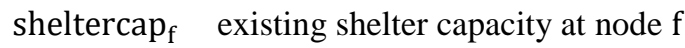

sheltercost $_{\mathrm{f}}$ construction cost of new shelter capacity at node $\mathrm{f}$

shelternewcap $_{\mathrm{f}}$ new shelter capacity at node $\mathrm{f}$

300 TIMECOST $_{e, f}$ average traveling time cost from node e to $\mathrm{f}$

trans $_{\mathrm{e}, \mathrm{f}, \mathrm{g}, \mathrm{h}}$ number of persons traveling from node e to $\mathrm{f}$ at time $\mathrm{g}$ for scenario $\mathrm{h}$

transcap $_{e, f}$ existing transportation capacity between nodes e and $\mathrm{f}$

transcost $t_{e, f} \quad$ construction cost of new transportation capacity between nodes e and $\mathrm{f}$

transnewcap ${ }_{e, f}$ new transportation capacity between nodes e and $\mathrm{f}$

\section{References}

Azam, M., Kim, H.S., Maeng, S.J.: Development of flood alert application in Mushim stream watershed Korea, Int. J. Disast.

Risk Re., 21, 11-26, doi:10.1016/j.ijdrr.2016.11.008, 2017. 
Nat. Hazards Earth Syst. Sci. Discuss., https://doi.org/10.5194/nhess-2017-325

Manuscript under review for journal Nat. Hazards Earth Syst. Sci.

Discussion started: 26 October 2017

(c) Author(s) 2017. CC BY 4.0 License.

Barbarosoglu, G., Arda, Y.: A two-stage stochastic programming framework for transportation planning in disaster response, J. Oper. Res. Soc., 55, 43-53, doi:10.1057/palgrave.jors.2601652, 2004.

Baydogan, M.G., Runger, G., Tuv, E.: A bag-of-features framework to classify time series, IEEE T. Pattern Anal., 35, 27962802, doi:10.1109/TPAMI.2013.72., 2013.

Behley, J., Steinhage, V., Cremers, A.B.: Laser-based segment classification using a mixture of bag-of-words, In: Proceedings of the 2013 IEEE/RSJ International Conference on Intelligent Robots and Systems (IROS), Tokyo, Japan, November 3-7, pp. 4195-4200, doi:10.1109/IROS.2013.6696957, 2013.

Bozorgi-Amiri, A., Jabalameli, M.S., Al-e-Hashem, S.M.J.M.: A multi-objective robust stochastic programming model for disaster relief logistics under uncertainty, OR Spectrum, 35, 905-933, doi:10.1007/s00291-011-0268-x, 2013.

Brauckhoff, D., Salamatian, K., May, M.: Applying PCA for traffic anomaly detection: Problems and solutions, In: Proceedings of the IEEE INFOCOM 2009, Rio de Janeiro, Brazil, April 19-25, pp. 2866-2870, doi:10.1109/INFCOM.2009.5062248, 2009.

Bretschneider, S.: Mathematical Models for Evacuation Planning in Urban Areas, Springer, New York, 2012.

Calvello, M., d'Orsi, R.N., Piciullo, L., Paes, N., Magalhaes, M., Lacerda, W.A.: The Rio de Janeiro early warning system for rainfall-induced landslides: analysis of performance for the years 2010-2013, Int. J. Disast. Risk Re., 12, 3-15 , doi:10.1016/j.ijdrr.2014.10.005, 2015.

Candès, E.J., Li, X., Ma, Y., Wright, J.: Robust principal component analysis? J. ACM, 58, 1-37, doi:10.1145/1970392.1970395, 2011.

Chen, W., He, B., Zhang, L., Nover, D.: Developing an integrated 2D and 3D WebGIS-based platform for effective landslide hazard management, Int. J. Disast. Risk Re., 20, 26-38, doi:10.1016/j.ijdrr.2016.10.003, 2016.

Cheng, J.D., Huang, Y.C., Wu, H.L., Yeh, J.L., Chang, C.H.: Hydrometeorological and landuse attributes of debris flows and debris floods during typhoon Toraji, July 29-30, 2001 in central Taiwan, J. Hydrol., 306, 161-173, doi:10.1016/j.jhydrol.2004.09.007, 2005.

Dean, J., Ghemawat, S.: MapReduce: simplified data processing on large clusters, Commun. ACM, 51, 107-113, doi:10.1145/1327452.1327492, 2008.

Fan, J.C., Huang, H.Y., Liu, C.H., Yang, C.H., Guo, J.J., Chang, C.F., Chang, Y.C.: Effects of landslide and other physiographic factors on the occurrence probability of debris flows in central Taiwan, Environ. Earth Sci., 74, 17851801, doi:10.1007/s12665-015-4187-z, 2015.

Gui, Z.W.,Yeh, Y.R.: Time series classification with temporal bag-of-words model, in: S.M. Cheng, M.Y. Day (Eds.), Proceedings of the 19th International Conference, TAAI 2014, LNAI 8916, Taipei, Taiwan, November 21-23, pp. 145153, doi:10.1007/978-3-319-13987-6_14, 2014.

Keefer, D.K., Wilson, R.C., Mark, R.K., Brabb, E.E., Brown III, W.M., Ellen, S.D., Harp, E.L., Wieczorek, G.F., Alger, C.S., Zatkin, R.S.: Real-time landslide warning during heavy rainfall, Science, 238, 921-925, doi:10.1126/science.238.4829.921, 1987. 
Nat. Hazards Earth Syst. Sci. Discuss., https://doi.org/10.5194/nhess-2017-325

Manuscript under review for journal Nat. Hazards Earth Syst. Sci.

Discussion started: 26 October 2017

(c) Author(s) 2017. CC BY 4.0 License.

Khan, N.Y., McCane, B., Wyvill, G.: Homography based visual bag of word model for scene matching in indoor environments, In: Proceedings of Image and Vision Computing New Zealand, 2011.

Lee, S., Pradhan, B.: Landslide hazard mapping at Selangor, Malaysia using frequency ratio and logistic regression models, Landslides., 4, 33-41, doi:10.1007/s10346-006-0047-y, 2007.

Lee, Y.J., Yeh,Y.R., Wang, Y.C.F.: Anomaly detection via online oversampling principal component analysis, IEEE T. Knowl. Data En., 25, 1460-1470, doi:10.1109/TKDE.2012.99, 2013.

Liang, W.J., Zhuang, D.F., Jiang, D., Pan, J.J., Ren, H.Y.: Assessment of debris flow hazards using a Bayesian Network, Geomorphology., 171, 94-100, doi:10.1016/j.geomorph.2012.05.008, 2012.

Lin, J., Khade, R., Li, Y.: Rotation-invariant similarity in time series using bag-of-patterns representation, J. Intell. Inf. Syst., 39, 287-315, doi:10.1007/s10844-012-0196-5, 2012.

Manandhar, S., Pratoomchai, W., Ono, K., Kazama, S., Komori, D.: Local people's perceptions of climate change and related hazards in mountainous areas of northern Thailand, Int. J. Disast. Risk Re., 11, 47-59, doi:10.1016/j.ijdrr.2014.11.002, 2015.

Marjanovic, M., Kovacevic, M., Bajat, B., Vozenilek, V.: Landslide susceptibility assessment using SVM machine learning algorithm, Eng. Geol., 123, 225-234, doi:10.1016/j.enggeo.2011.09.006, 2011.

Masaba, S., Mungai, D.N., Isabirye, M., Nsubuga, H.: Implementation of landslide disaster risk reduction policy in Uganda, Original Research Article, Int. J. Disast. Risk Re., doi:10.1016/j.ijdrr.2017.01.019, 2017.

Promper, C., Gassner, C., Glade, T.: Spatiotemporal patterns of landslide exposure-a step within future landslide risk analysis on a regional scale applied in Waidhofen/Ybbs Austria, Int. J. Disast. Risk Re., 12, 25-33, doi:10.1016/j.ijdrr.2014.11.003, 2015.

Pourrahmani, E., Delavar, M.R., Mostafavi, M.A.: Optimization of an evacuation plan with uncertain demands using fuzzy credibility theory and genetic algorithm, Int. J. Disast. Risk Re., 14, 357-372, doi:10.1016/j.ijdrr.2015.09.002, 2015.

Pradhan, B.: A comparative study on the predictive ability of the decision tree, support vector machine and neuro-fuzzy models in landslide susceptibility mapping using GIS, Comput. Geosci., 51, 350-365, doi:10.1016/j.cageo.2012.08.023, 2013.

Ringberg, H., Soule, A., Rexford, J., Diot, C.: Sensitivity of PCA for traffic anomaly detection, ACM SIGMETRICS Perform. Eval. Rev., 35, 109-120, doi:10.1145/1269899.1254895, 2007.

Takahashi, T.: Debris flow, Annu. Rev. Fluid Mech., 13, 57-77, doi:10.1146/annurev.fl.13.010181.000421, 1981.

Wang, J., Liu, P., She, M.F., Nahavandi, S., Kouzani, A.: Bag-of-words representation for biomedical time series classification, Biomed. Signal Process. Control, 8, 634-644, doi:10.1016/j.bspc.2013.06.004, 2013.

Wieczorek, G.F.: Effect of rainfall intensity and duration on debris flows in central Santa Cruz Mountains, California, Rev. Eng. Geol., 7 ,93-104, doi:10.1130/REG7-p93, 1987. 
Nat. Hazards Earth Syst. Sci. Discuss., https://doi.org/10.5194/nhess-2017-325

Manuscript under review for journal Nat. Hazards Earth Syst. Sci.

Discussion started: 26 October 2017

(c) Author(s) 2017. CC BY 4.0 License.

(c) (i)

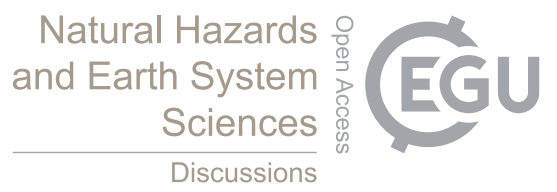

Wood, N., Jones, J., Schmidtlein, M., Schelling, J., Frazier, T.: Pedestrian flow-path modeling to support tsunami evacuation 375 and disaster relief planning in the U.S. Pacific Northwest, Int. J. Disast. Risk Re., 18, 41-55, doi:10.1016/j.ijdrr.2016.05.010, 2016.

Xu, C., Dai, F., Xu, X., Lee, Y.H.: GIS-based support vector machine modeling of earthquake-triggered landslide susceptibility in the Jianjiang River watershed, China, Geomorphology, 145-146, 70-80, doi:10.1016/j.geomorph.2011.12.040, 2012.

380 Xu, J., Yin, X., Chen, D., An, J., Nie, G.: Multi-criteria location model of earthquake evacuation shelters to aid in urban planning, Int. J. Disast. Risk Re., 20, 51-62, doi:10.1016/j.ijdrr.2016.10.009, 2016.

Yao, X., Tham, L.G., Dai, F.C.: Landslide susceptibility mapping based on Support Vector Machine: A case study on natural slopes of Hong Kong, China, Geomorphology, 101, 572-582, doi:10.1016/j.geomorph.2008.02.011, 2008. 
Nat. Hazards Earth Syst. Sci. Discuss., https://doi.org/10.5194/nhess-2017-325

Manuscript under review for journal Nat. Hazards Earth Syst. Sci.

Discussion started: 26 October 2017

(c) Author(s) 2017. CC BY 4.0 License.

(c) (i)

\section{Figure captions}

385 Figure 1. Case studies of Shenmu village and Fengchiu, Taiwan.

Figure 2. Flowchart of bag-of-words and anomaly-detection PCA debris flow prediction algorithms and stochastic programming of evacuation planning.

Figure 3. Rainfall of debris flow events in July, 13th, 2011.

Figure 4. Soil water content of debris flow events in July, 13th, 2011.

390 Figure 5. Rainfall of debris flow events in November 10th, 2011.

Figure 6. Soil water content of debris flow events in November 10th, 2011.

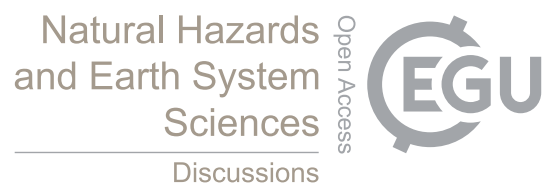


Nat. Hazards Earth Syst. Sci. Discuss., https://doi.org/10.5194/nhess-2017-325

Manuscript under review for journal Nat. Hazards Earth Syst. Sci.

Discussion started: 26 October 2017

(C) Author(s) 2017. CC BY 4.0 License.

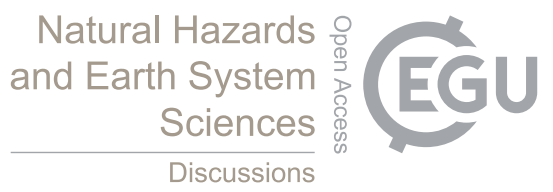

Table 1. Bag-of-words and anomaly-detection PCA predictions of debris flows on Shenmu village.

\begin{tabular}{|c|c|c|c|c|}
\hline & \multirow[b]{2}{*}{$\begin{array}{c}\text { Actual debris flow } \\
\text { events }\end{array}$} & \multicolumn{3}{|c|}{ Prediction method } \\
\hline & & $\begin{array}{c}\text { Bag-of-words and } \\
\text { anomaly-detection } \\
\text { PCA }\end{array}$ & $\begin{array}{c}\text { Effective } \\
\text { accumulative } \\
\text { rainfall method }\end{array}$ & Red warning \\
\hline Event time & $2011 / 07 / 13 / 14: 30$ & $2011 / 07 / 19 / 03: 30$ & $2012 / 06 / 10 / 20: 30$ & $2012 / 06 / 10 / 17: 00$ \\
\hline$(\mathrm{UTC}+8: 00$ & 2011/07/19/23:00 & $2012 / 05 / 03 / 17: 40$ & $2013 / 05 / 21 / 05: 40$ & 2012/08/02/14:00 \\
\hline \multirow[t]{11}{*}{ Taipei time) } & 2011/11/10/03:20 & 2012/05/20/09:30 & $2013 / 07 / 13 / 06: 50$ & 2013/07/13/03:00 \\
\hline & 2012/05/04/16:00 & $2012 / 06 / 10 / 12: 10$ & $2013 / 08 / 22 / 05: 50$ & 2013/08/21/20:00 \\
\hline & 2012/06/10/19:00 & 2012/08/02/06:20 & $2014 / 07 / 23 / 16: 30$ & 2014/07/23/14:00 \\
\hline & 2013/05/19/07:00 & $2012 / 08 / 16 / 21: 50$ & $2015 / 05 / 25 / 02: 10$ & 2015/08/08/17:00 \\
\hline & 2013/07/13/07:00 & $2013 / 05 / 17 / 05: 50$ & $2015 / 08 / 09 / 02: 10$ & 2015/09/29/02:00 \\
\hline & $2014 / 05 / 20 / 12: 50$ & 2013/05/19/08:40 & 2015/09/29/03:20 & \\
\hline & & $2013 / 05 / 21 / 06: 30$ & & \\
\hline & & 2013/07/13/02:00 & & \\
\hline & & $2013 / 08 / 21 / 21: 10$ & & \\
\hline & & $2014 / 05 / 20 / 14: 10$ & & \\
\hline & & $2015 / 05 / 26 / 15: 10$ & & \\
\hline $\begin{array}{c}\text { Prediction } \\
\text { rate }^{\mathrm{a}}\end{array}$ & & $75 \%$ & $25 \%$ & $25 \%$ \\
\hline $\begin{array}{l}\text { Prediction } \\
\text { accuracy }^{b}\end{array}$ & & $46 \%$ & $25 \%$ & $29 \%$ \\
\hline
\end{tabular}

a Prediction rate: prediction percentage of actual debris flow.

${ }^{\mathrm{b}}$ Prediction accuracy: rate of accurate prediction. 
Nat. Hazards Earth Syst. Sci. Discuss., https://doi.org/10.5194/nhess-2017-325

Manuscript under review for journal Nat. Hazards Earth Syst. Sci.

Discussion started: 26 October 2017

(C) Author(s) 2017. CC BY 4.0 License.

(c) (i)

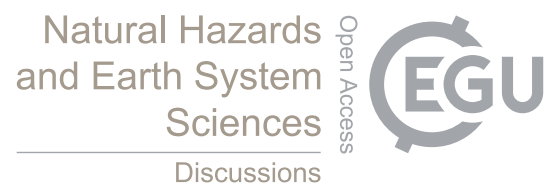

Table 2. Bag-of-words and anomaly-detection PCA prediction of debris flows in Fengchiu.

\begin{tabular}{ccccc}
\hline & Actual debris flow & \multicolumn{3}{c}{ Prediction method } \\
\cline { 3 - 5 } & events & $\begin{array}{c}\text { Bag-of-words and } \\
\text { anomaly-detection } \\
\end{array}$ & $\begin{array}{c}\text { Effective } \\
\text { accumulative } \\
\text { PCA }\end{array}$ & Red warning \\
\hline Event time & $2012 / 05 / 03 / 16: 00$ & $2012 / 05 / 03 / 15: 40$ & $2012 / 06 / 12 / 13: 40$ & $2012 / 06 / 11 / 20: 00$ \\
$($ UTC +8:00 & $2012 / 05 / 20 / 09: 50$ & $2012 / 08 / 02 / 08: 50$ & $2012 / 08 / 02 / 08: 00$ \\
Taipei time) & $2012 / 08 / 02 / 06: 50$ & $2013 / 07 / 13 / 07: 00$ & $2013 / 07 / 12 / 23: 00$ \\
& $2013 / 05 / 19 / 09: 20$ & $2013 / 08 / 22 / 07: 20$ & $2013 / 08 / 21 / 20: 00$ \\
\hline $\begin{array}{c}\text { Prediction } \\
\text { rate }\end{array}$ & $100 \%$ & $0 \%$ & $0 \%$ \\
Prediction $_{\text {accuracy }}$ & $25 \%$ & $0 \%$ & $0 \%$ \\
\hline
\end{tabular}

a Prediction rate: prediction percentage of actual debris flow.

${ }^{b}$ Prediction accuracy: rate of accurate prediction. 
Nat. Hazards Earth Syst. Sci. Discuss., https://doi.org/10.5194/nhess-2017-325

Manuscript under review for journal Nat. Hazards Earth Syst. Sci.

Discussion started: 26 October 2017

(c) Author(s) 2017. CC BY 4.0 License.

\section{Natural Hazards and Earth System Sciences \\ Discussions}

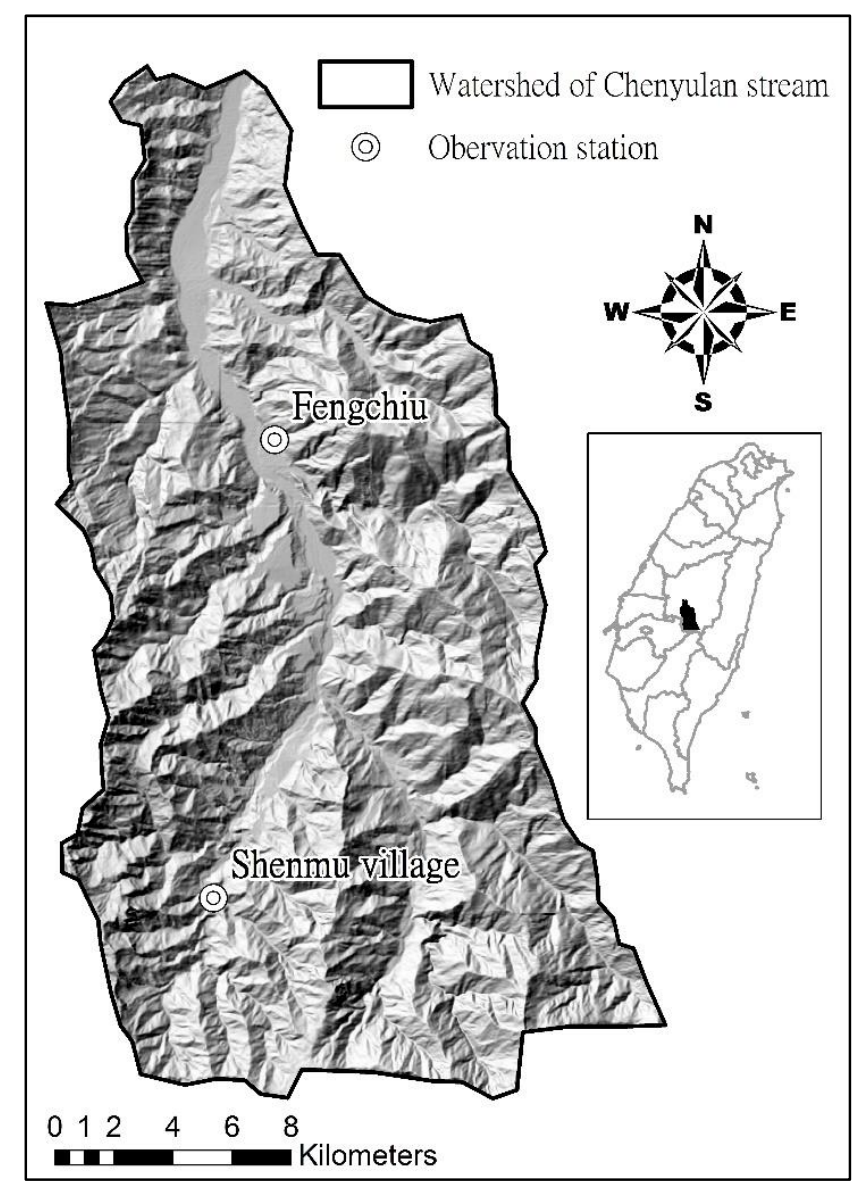

Figure 1. Case studies of Shenmu village and Fengchiu, Taiwan. 
Nat. Hazards Earth Syst. Sci. Discuss., https://doi.org/10.5194/nhess-2017-325

Manuscript under review for journal Nat. Hazards Earth Syst. Sci.

Discussion started: 26 October 2017

(c) Author(s) 2017. CC BY 4.0 License.

(c) (i)
Natural Hazards and Earth System

Sciences

Discussions

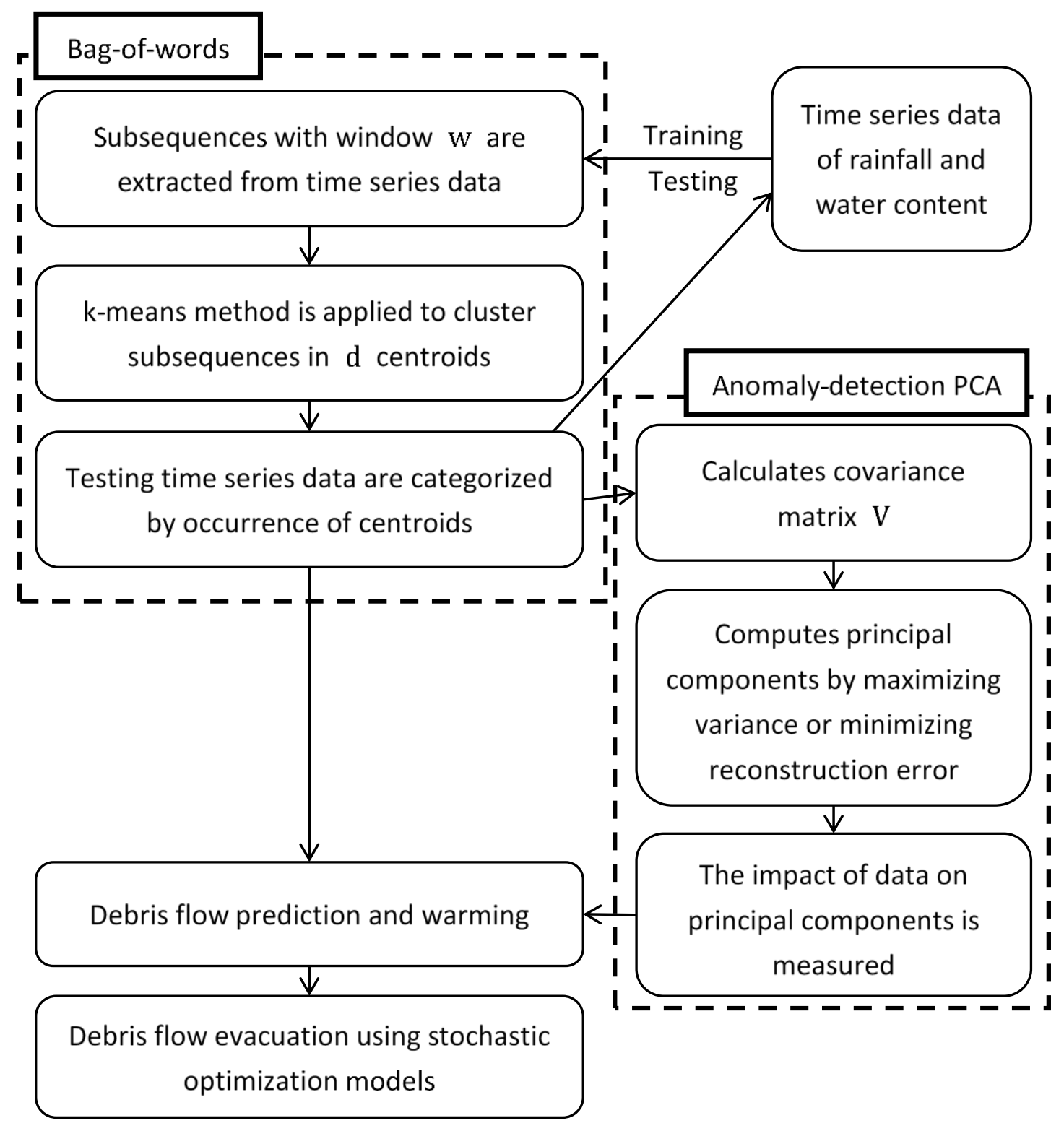

Figure 2. Flowchart of bag-of-words and anomaly-detection PCA debris flow prediction algorithms and stochastic programming of evacuation planning. 
Nat. Hazards Earth Syst. Sci. Discuss., https://doi.org/10.5194/nhess-2017-325

Manuscript under review for journal Nat. Hazards Earth Syst. Sci.

Discussion started: 26 October 2017

(c) Author(s) 2017. CC BY 4.0 License.

(c) (i)

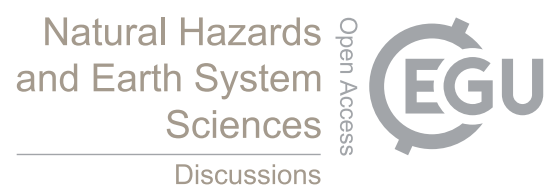

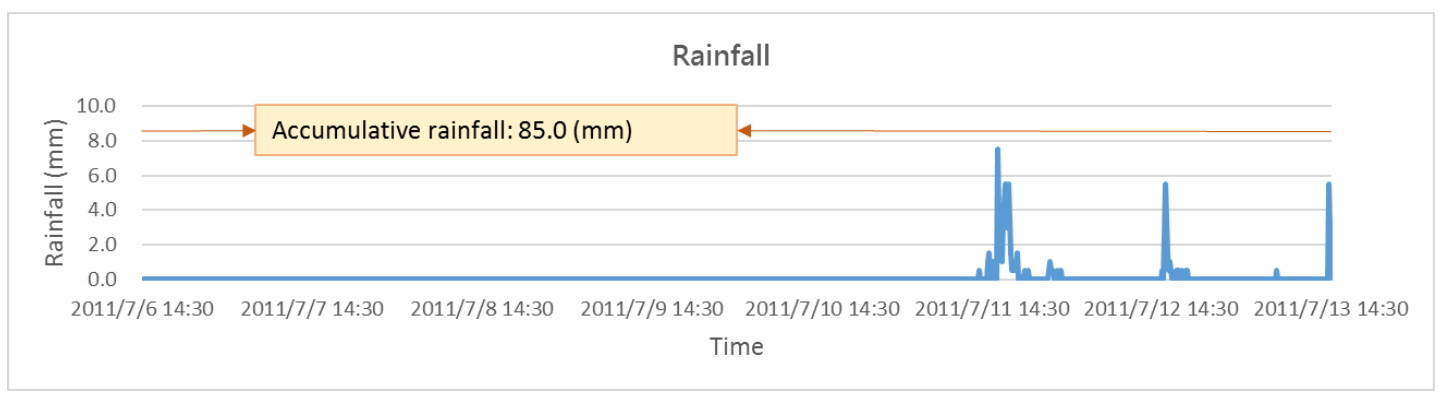

410 Figure 3. Rainfall of debris flow events in July, 13th, 2011. 
Nat. Hazards Earth Syst. Sci. Discuss., https://doi.org/10.5194/nhess-2017-325

Manuscript under review for journal Nat. Hazards Earth Syst. Sci.

Discussion started: 26 October 2017

(c) Author(s) 2017. CC BY 4.0 License.

(c) (1)

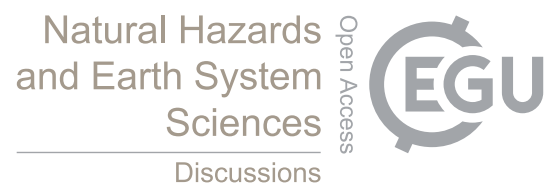

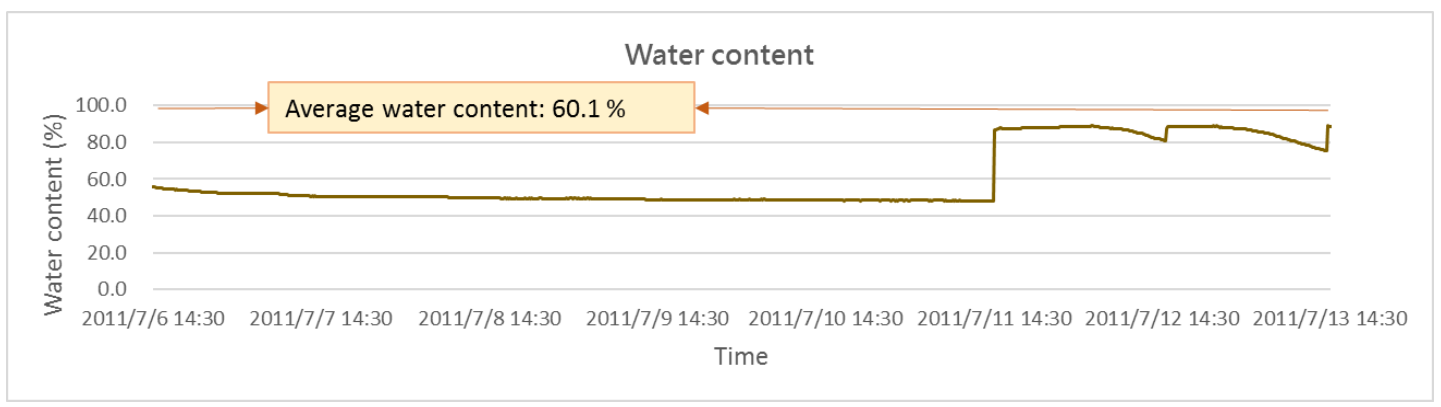

Figure 4. Soil water content of debris flow events in July, 13th, 2011. 
Nat. Hazards Earth Syst. Sci. Discuss., https://doi.org/10.5194/nhess-2017-325

Manuscript under review for journal Nat. Hazards Earth Syst. Sci.

Discussion started: 26 October 2017

(c) Author(s) 2017. CC BY 4.0 License.

(c) (1)

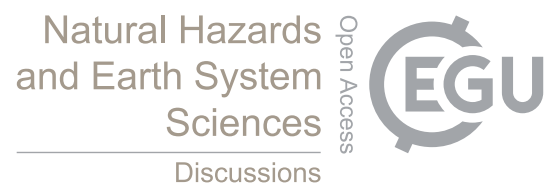

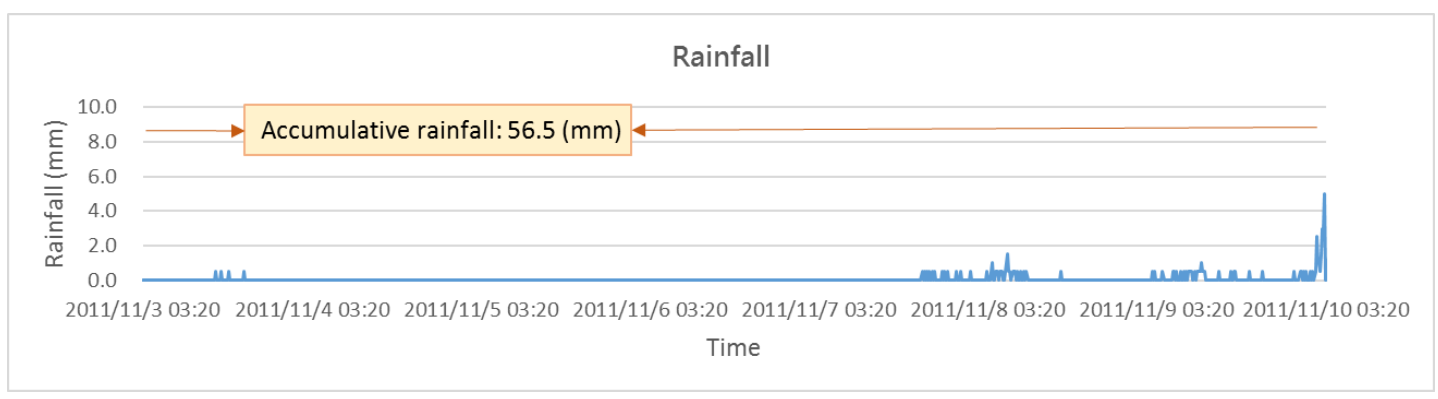

Figure 5. Rainfall of debris flow events in November 10th, 2011. 
Nat. Hazards Earth Syst. Sci. Discuss., https://doi.org/10.5194/nhess-2017-325

Manuscript under review for journal Nat. Hazards Earth Syst. Sci.

Discussion started: 26 October 2017

(c) Author(s) 2017. CC BY 4.0 License.

(c) (i)

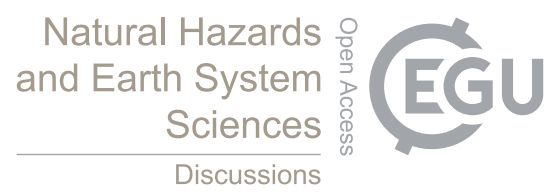

420

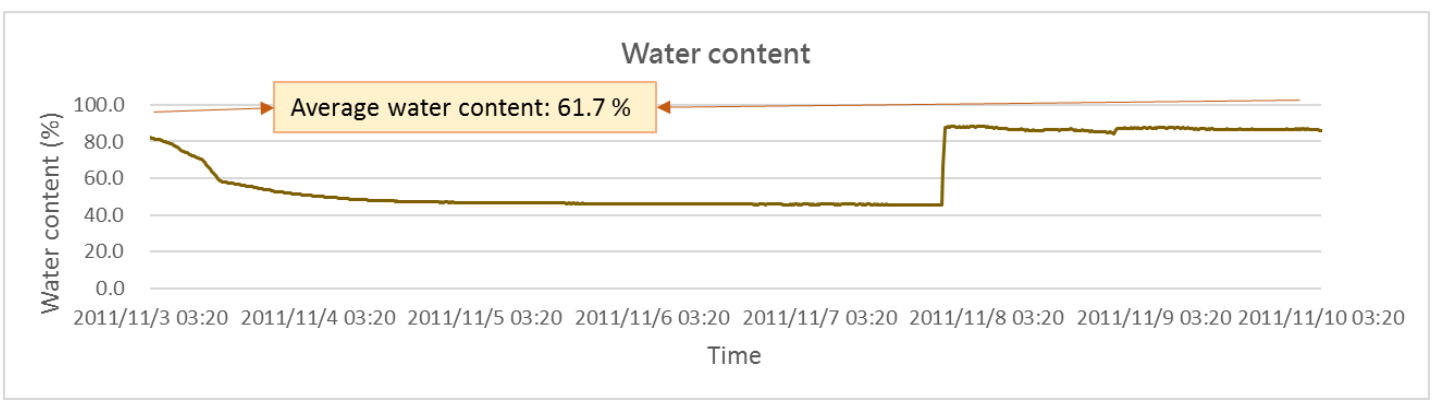

Figure 6. Soil water content of debris flow events in November $10^{\text {th }}, 2011$. 